\title{
Mutational Activation of FGFR3 is Not Involved in the Development of Prostate Cancer
}

\author{
Stella Koufou ${ }^{a}$ Jens-Claudio Lunz ${ }^{d}$ Albert Borchardt ${ }^{e}$ Bastian Keck ${ }^{f}$ \\ Burkhard Kneitz $^{\text {h }}$ Nadine T. Gaisa ${ }^{i}$ Christian Hafner ${ }^{b}$ Christian Giedlc \\ Tilman T. Rau ${ }^{\mathrm{g}}$ Anja Rogler ${ }^{\mathrm{a}}$ Wolf F. Wieland ${ }^{\mathrm{a}} \quad$ Arndt Hartmann $^{\mathrm{g}}$ \\ Robert Stoehrg
}

Departments of a Urology and ${ }^{\mathrm{b}}$ Dermatology, and ${ }^{\mathrm{C}}$ Institute of Pathology, University of Regensburg, Regensburg, ${ }^{\mathrm{d}}$ Group Practice for General Medicine, Siegenburg, e Urological Joint Practice, Medical Center Roethelheimpark, and ${ }^{\mathrm{f}}$ Department of Urology and $\mathrm{g}$ Institute of Pathology, University Hospital Erlangen, Erlangen, hepartment of Urology, University of Würzburg, Würzburg, and 'Institute of Pathology, University Hospital of the RWTH

Aachen, Aachen, Germany

\section{Key Words}

Prostate cancer $\cdot$ FGFR3 $\cdot$ Incidental prostate cancer

\begin{abstract}
Objective: The mutational constitutive activation of FGFR3 has been discovered in several malignancies but only limited data on FGFR3 mutations in prostate cancer are available. Most recently, activating FGFR3 mutations were described as being associated with low-grade prostate tumors. Therefore, we investigated the FGFR3 mutation status in a comprehensive series of prostate tumors. Methods: 102 archival formalin-fixed paraffin-embedded prostate tumors of patients treated with radical prostatectomy [with a low-grade subgroup (Gleason score $\leq 6$ ) of 29 patients] as well as 29 incidental prostate tumors [low-grade tumors (Gleason score $\leq 6) ; n=22$ ] and 16 benign prostatic hyperplasia samples obtained by transurethral resection of the prostate were investigated. After microdissection and DNA isolation, all FGFR3 mutation hotspots discovered in human malignancies
\end{abstract}

\section{KARGER}

Fax +41613061234 E-Mail karger@karger.ch www.karger.com

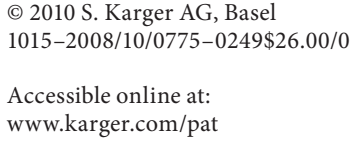

were analyzed using the $\mathrm{SNaPshot}{ }^{\odot}$ approach or restriction fragment length polymorphism (RFLP) analysis. Results: All cases could successfully be analyzed by SNaPshot; 80 cases were investigated using RFLP. No mutation in FGFR3 could be detected in any of the analyzed cases. Conclusion: The most recently reported FGFR3 mutations in low-grade prostate tumors could not be verified in our series. There were also no mutations in prostate tumors from patients with concomitant bladder tumors as reported previously. These data suggest that the mutational activation of FGFR3 plays no important role in prostate carcinogenesis, which is in accordance with previous studies performed on smaller tumor cohorts.

Copyright $\odot 2010$ S. Karger AG, Basel

\section{Introduction}

Fibroblast growth factors (FGF) and their receptors (FGFR) have been demonstrated to be involved in multiple biological processes, e.g. differentiation, motility, or

Dr. Robert Stoehr

Institute of Pathology, University Hospital Erlangen

Universitaetsstrasse 22

DE-91054 Erlangen (Germany)

Tel. +499131 852 6088, Fax +499131852 5741, E-Mail robert.stoehr@uk-erlangen.de 
proliferation, and this ligand-receptor system plays an important role in tumorigenesis [1]. A deregulation of the FGF/FGFR pathway was also described in prostate cancer (PCa). A closer functional evaluation of this pathway even suggested this system to be a potential target for therapy againts human $\mathrm{PCa}$ [2]. An overexpression of various members of the FGF/FGFR system was detected in PCa (e.g. FGFR1 and FGFR4 proteins), and a link between the FGF/FGFR system and an aggressive biological phenotype of PCa could be demonstrated recently (FGF8 protein expression in bone metastasis of $\mathrm{PCa})[3,4]$.

In recent years, research on the FGF/FGFR system has spotlighted 1 member of the FGFR gene family. Alterations of FGFR3 were identified in various malignant (e.g. bladder cancer and cervix cancer) [5] and benign (e.g. seborrheic keratoses and epidermal nevi) $[6,7]$ tumors, and these alterations could also be linked to a favorable course of the disease in noninvasive papillary bladder cancer [8]. Additionally, in bladder cancer FGFR3 mutations were linked to protein overexpression, but overexpression without concomitant mutations was especially found in advanced tumors [9]. In PCa the role of FGFR3 is still not clear. Studies investigating FGFR3 expression at the protein and mRNA levels could not find FGFR3 overexpression in benign prostatic hyperplasia $(\mathrm{BPH})$ or $\mathrm{PCa}[2,3,10]$. The mutation status of FGFR3 in PCa is a controversial topic of discussion at the moment. Three studies investigated FGFR3 mutations showing no evidence for FGFR3 mutations in PCa [11-13]. Most recently, Hernández et al. [14] reported a remarkable FGFR3 mutation frequency in low-grade PCa and in PCa in patients with other associated malignancies.

To further this discussion we investigated the FGFR3 mutation status in a comprehensive series of prostate tumors.

\section{Material and Methods}

\section{Tissue Samples}

Overall, 102 unselected archival formalin-fixed paraffinembedded prostate tumors obtained by radical prostatectomy [among them low-grade tumors (Gleason score $\leq 6$ ); $n=29$ ], as well as 29 incidental prostate tumors [among them low-grade tumors (Gleason score $\leq 6$ ); $\mathrm{n}=22$ ], and $16 \mathrm{BPH}$ samples obtained by transurethral resection of the prostate, were analyzed. Classification of the tumors was performed according to the TNM classification (International Union Against Cancer, Geneva, Switzerland) [15] and the World Health Organization (WHO) classification of prostate tumors [16]. The clinical and histopathological characteristics of patients and tumors are shown in table 1.
Table 1. Clinical and histopathological characteristics of the analyzed patients and tumors

\begin{tabular}{llllr}
\hline & $\begin{array}{l}\text { Radical prostatec- } \\
\text { tomy group }\end{array}$ & $\begin{array}{l}\text { Incidental pros- } \\
\text { tate cancer group }\end{array}$ \\
\hline $\begin{array}{l}\text { Number } \\
\text { Age, years }\end{array}$ & 102 & 29 & \\
$\quad$ Median (range) & $66(46-80)$ & & $73(60-83)$ & \\
$\quad$ Mean \pm SD & $64.6 \pm 6.1$ & & $72.4 \pm 6.1$ & 27 \\
Stage & pT1-3a & 81 & pT1a-1c & 22 \\
Gleason score & pT3b-3c & 21 & pT2a-pT2b & 2 \\
& $7-6$ & 29 & $3-6$ & 7 \\
& $7-10$ & 48 & 7 & - \\
& no data available & 23 & - & - \\
& & & & \\
& & &
\end{tabular}

\section{DNA Isolation}

Serial sections $(5 \mu \mathrm{m})$ from the tissue blocks were deparaffinized and rehydrated for microdissection, and areas with $\geq 80 \%$ tumor cells were marked on an H\&E-stained section by an experienced surgical pathologist before microdissection. The marked tissue sections were then used as templates for microdissection which was performed manually with sterile needles after methylene blue staining. DNA was isolated using a High Pure PCR Template Preparation $\mathrm{Kit}^{\odot}$ (Roche, Mannheim, Germany) according to the manufacturer's instructions. A previously described highly sensitive $\mathrm{SNaPshot}{ }^{\odot}$ multiplex assay, based on the SNaPshot Multiplex System assay (Applied Biosystems, Foster City, Calif., USA), was used to screen for activating FGFR3 point mutations. Using this assay, screening could be performed for 11 known mutations found in bladder tumors and other epithelial tumors (R248C, S249C, G372C, S373C, Y375C, G382R, A393E, K652E, K652M, K652Q, and K652T) [7, 17]. Extended primers were separated by capillary electrophoresis in an automatic sequencer, and the presence or absence of a mutation was indicated by the incorporated wild-type or mutant-labeled dideoxynucleotide. When a mutation is present, a second peak originating from the mutated nucleotide will appear next to the wild-type peak in the electropherogram. In order to analyze a previously reported additional activating FGFR3 mutation in codon 697 (G697C) [18], we used the restriction fragment length polymorphism (RFLP) approach which was described in detail previously [19].

\section{Results}

The FGFR3 SNaPshot analysis could successfully be performed on all $131 \mathrm{PCa}$ samples and on all $16 \mathrm{BPH}$ samples. In all samples only the wild-type sequence of FGFR3 was found, and none of the analyzed samples showed an FGFR3 mutation (fig. 1a). For the RFLP analysis a higher amount of DNA was necessary compared to the SNaPshot analysis. Therefore, only a subset of prostate tumors 
Fig. 1. a Representative FGFR3 analysis by $\mathrm{SNaPshot}$ assay. DNA from a prostate tumor (pT3aG3, Gleason score $=7$ ) showing the wild-type sequence in the known FGFR3 mutation hotspots. b RFLP analysis of FGFR 3 codon 697. Polymerase chain reaction fragments (209 bp) containing the wild-type sequence in codon 697 could be digested with MspI $(100+109$ bp; both fragments appear as 1 band on the gel). In case of a mutation, the MspI site is destroyed. 1-4 = DNA from PCa samples; $5=$ DNA from the urothelial cell line UROtsa (representing normal urothelium) after MspI digestion; 6 = UROtsa DNA without MspI digestion; 7 = negative control $\left(\mathrm{H}_{2} \mathrm{O}\right)$; St. = Size standard. All analyzed samples showed the wild-type sequence for codon 697.
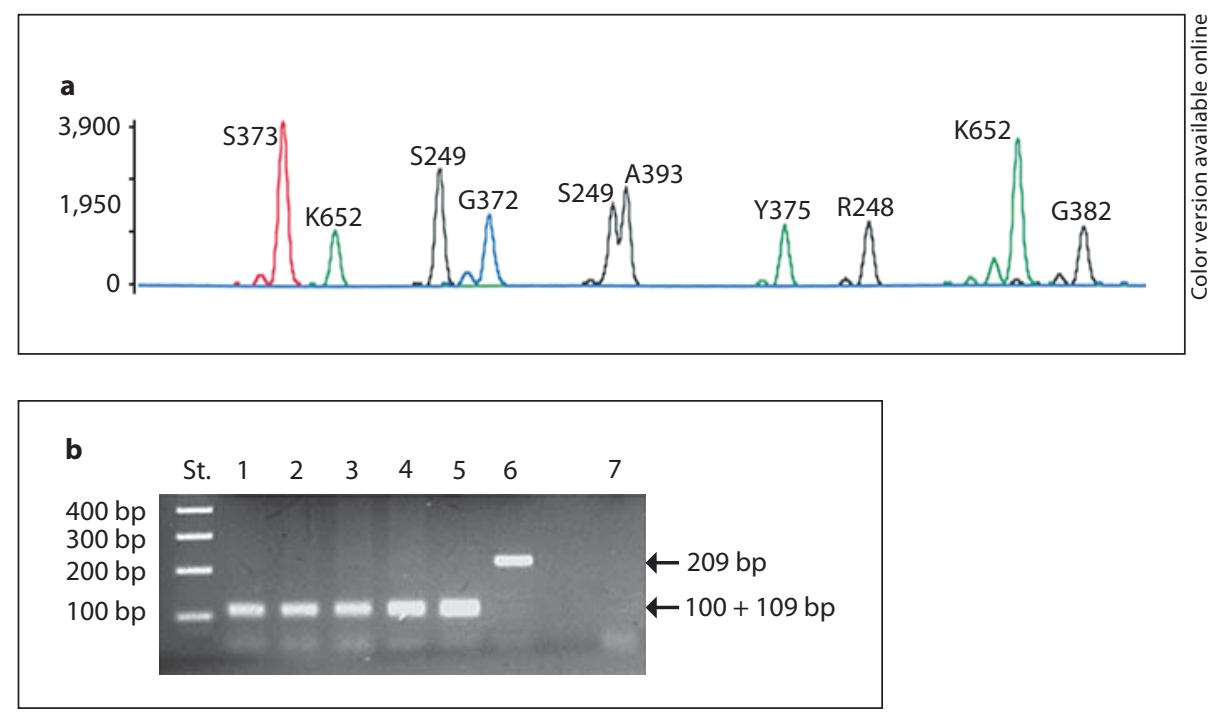

was available for the FGFR3 codon 697 analysis. All investigated samples showed the wild-type sequence for codon 697, and no mutation was detected (fig. 1b).

\section{Discussion}

Our results are contrary to those of the most recent study of Hernández et al. [14] which reported up to $18 \%$ FGFR3 mutations in low-grade PCa (combined Gleason score $=6$ ). We analyzed a larger cohort of low-grade PCa than the aforementioned study but did not find a mutation. We also screened a larger group of cases with a combined Gleason score of 7 which showed a mutation frequency of at least $3 \%$ in the study of Hernández et al. but, again, we only found the wild-type sequence in the FGFR3 mutation hotspots.

One explanation for the lack of FGFR3 mutations in our cohort could be a strong contamination of the material with nonneoplastic cells, which could make the detection of mutations impossible. However, great care was taken during microdissection to avoid the analysis of mixed cell populations. In addition, the SNaPshot assay used is very robust and highly sensitive, detecting $1 \mathrm{mu}-$ tant allele in a background of $97 \%$ wild-type alleles [17]. Therefore, contamination with normal cells is a very unlikely explanation for the lack of FGFR3 mutations in our study.

The lack of detection of the rare G697C mutation was also unlikely to be due to technical limitations because this mutation has only been reported in oral squamous cell carcinomas to date, and has not been analyzed in other tumor types so far. Therefore, the presented study is the first to report a lack of this rare mutation in PCa.

The highest number of FGFR3 mutations reported by Hernández et al. [14] was found in patients with additional tumors apart from PCa, i.e. bladder, skin, and colon tumors. We also screened our cohort for secondary tumors and found only 2 cases with bladder cancer $(1 \times \mathrm{pTa}$ low-grade without an FGFR3 mutation and $1 \times$ pT2 highgrade with an FGFR3 S249C mutation) and 1 case with colon adenoma. This showed that a secondary tumor is a rare event in PCa patients. None of the prostate tumors from these cases showed an FGFR3 mutation. Although it is known that patients with PCa or a family history of PCa have a higher risk of bladder and other secondary cancers $[20,21]$, the large PCa patient group with secondary bladder, colon, or skin tumors presented by Hernández et al. [14] did not reflect the general population. This highly selected patient group with up to 3 tumors in different locations might represent a population with a high overall risk of developing a malignancy. As stated in the aforementioned study, there was a remarkably high percentage of FGFR3 mutations in PCa patients with secondary bladder and skin tumors, both of which are known to be associated with FGFR3 mutations [5, 22]. Hernández et al. [14] also analyzed the FGFR 3 mutation status in these secondary tumors and the corresponding normal tissue in some cases, but a mutation was only detected in 1 bladder tumor and never in the normal tissue. Nevertheless, it could not completely be ruled out that these patients might present a mosaicism of FGFR3 mutations as has already been 
shown for epidermal nevi [7]. This might explain the high frequency of FGFR3-associated tumors in the subjects from the patient cohort of Hernández et al. [14], although the lack of FGFR3 mutation in the secondary tumors would argue against this possibility.

Interestingly, FGFR 3 mutations affecting codon 650 in spermatocytic seminomas were recently described [23]. These tumors are a rare variant of testicular germ cell tumors and show a later mean age of onset (approx. 55 years) than common testicular germ cell tumors (approx. 25-35 years). This study also described increased levels of FGFR 3 mutations in sperm from healthy donors at an advanced age. One might speculate that FGFR3 mutations could occur in specific cells or a subset of tissues which are under constant hormonal influence at an advanced age. But this aspect remains highly speculative and lacks any experimental evidence.

In conclusion, the results of our study revealed no evidence of an involvement of the FGFR3 mutation in pros- tate carcinogenesis. Our data are in line with previous published FGFR 3 analyses on smaller prostate cancer cohorts and are strengthened by the inconspicuous FGFR3 expression in prostate tumors compared to nonmalignant prostate tissue. The high frequency of FGFR 3 mutations in low-grade PCa reported by Hernández et al. [14] could not be confirmed in our cohort and awaits urgent validation.

\section{Acknowledgement}

We thank A. Pietryga-Krieger, N. Niessl, and S. Götz for their excellent technical assistance. This study was supported by a grant from the University of Regensburg (ReForM C) to J.C.L., A.B., A.H., and R.S. Parts of this study were presented at the AACR Annual Meeting 2008 held from April 12 to 16 in San Diego, Calif., USA.

\section{References}

1 Grose R, Dickson C: Fibroblast growth factor signaling in tumorigenesis. Cytokine Growth Factor Rev 2005;16:179-186.

-2 Gowardhan B, Douglas DA, Mathers ME, McKie AB, McCracken SR, Robson CN, Leung HY: Evaluation of the fibroblast growth factor system as a potential target for therapy in human prostate cancer. Br J Cancer 2005;92:320-327.

-3 Sahadevan K, Darby S, Leung HY, Mathers ME, Robson CN, Gnanapragasam VJ: Selective over-expression of fibroblast growth factor receptors 1 and 4 in clinical prostate cancer. J Pathol 2007;213:82-90.

$\checkmark 4$ Valta MP, Tuomela J, Bjartell A, Valve E, Väänänen HK, Härkönen P: FGF-8 is involved in bone metastasis of prostate cancer. Int J Cancer 2008;123:22-31.

5 Capellen D, De Oliveira C, Ricol D, de Medina S, Bourdin J, Sastra-Garau X, Chopin D, Thiery JP, Radnanyi F: Frequent activating mutations of FGFR3 in human bladder and cervix carcinomas. Nat Genet 1999;23:1820.

-6 Hafner C, van Oers JM, Hartmann A, Landthaler M, Stoehr R, Blaszyk H, Hofstaedter F, Zwarthoff EC, Vogt T: High frequency of FGFR3 mutations in adenoid seborrheic keratoses. J Invest Dermatol 2006; 126:2404-2407.

7 Hafner C, van Oers JM, Vogt T, Landthaler M, Stoehr R, Blaszyk H, Hofstaedter F, Zwarthoff EC, Hartmann A: Mosaicism of activating FGFR3 mutations in human skin causes epidermal nevi. J Clin Invest 2006; 116:2201-2207.

8 Knowles MA: Role of FGFR3 in urothelial cell carcinoma: biomarker and potential therapeutic target. World J Urol 2007;25: 581-593.

9 Tomlinson DC, Baldo O, Harnden P Knowles MA: FGFR3 protein expression and its relationship to mutation status and prognostic variables in bladder cancer. J Pathol 2007;213:91-98.

10 Boget S, Cereser C, Parvaz P, Leriche A, Revol A: Fibroblast growth factor receptor 1 (FGFR1) is over-expressed in benign prostatic hyperplasia whereas FGFR2-IIIc and FGFR3 are not. Eur J Endocrinol 2001;145: 303-310.

-11 Naimi B, Latil A, Berthon P, Cussenot O: No evidence for fibroblast growth factor receptor 3 (FGFR-3) R248C/S249C mutations in human prostate cancer. Int J Cancer 2000;87: 455-456.

12 Sibley K, Stern P, Knowles MA: Frequency of fibroblast growth factor receptor 3 mutations in sporadic tumors. Oncogene 2001;20: 4416-4418.

13 Thomas RK, Baker AC, Debiasi RM, Winckler W, Laframboise T, Lin WM, Wang M, et al: High-throughput oncogene mutation profiling in human cancer. Nat Genet 2007; 39:347-351.

14 Hernández S, de Muga S, Agell L, Juanpere N, Esgueva R, Lorente JA, Nojal S, Serrano S, Lloreta J: FGFR3 mutations in prostate cancer: association with low-grade tumors. Mod Pathol 2009;22:848-856.

15 Sobin LH, Wittekind C: TNM Classification of Malignant Tumors, ed 6. New York, Wiley-Liss, 2002.

16 Eble J, Sauter G, Epstein JI, Sesterhenn IA (eds): Classification of Tumours. Pathology and Gentics of Tumours of the Urinary Sys- tem and Male Genital organs. Lyon, World Health Organization, 2004.

17 van Oers JM, Lurkin I, van Exsel AJ, Nijsen Y, van Rhijn BW, van der Aa MN, Zwarthoff EC: A simple and fast method for the simultaneous detection of nine fibroblast growth factor receptor 3 mutations in bladder cancer and voided urine. Clin Cancer Res 2005;11: 7743-7748

18 Zhang Y, Hiraishi Y, Wang H, Sumi K, Hayashido Y, Toratani S, Kan M, Sato JD, Okamoto T: Constitutive activating mutation of the FGFR3b in oral squamous cell carcinomas. Int J Cancer 2005;117:166-168.

19 Woenckhaus M, Merk J, Stoehr R, Schaeper F, Gaumann A, Wiebe K, Hartmann A, Hofstaedter F, Dietmaier W: Prognostic value of FHIT, CTNNB1, and MUC1 expression in non-small cell lung cancer. Hum Pathol 2008;39:126-136

20 Singh A, Kinoshita Y, Rovito PM, Landas S, Silberstein J, Nsouli I, Wang CY, Haas GP: Higher than expected association of clinical prostate and bladder cancers. J Urol 2005; 173:1526-1529.

21 Zhang H, Bermejo JL, Sundquist J, Hemminki K: Prostate cancer as a first and second cancer: effect of familial history. Br J Cancer 2009;101:935-939.

-22 Hafner C, Vogt T, Hartmann A: FGFR3 mutations in benign skin tumors. Cell Cycle 2006:5:2723-2728.

23 Goriely A, Hansen RM, Taylor IB, Olesen IA, Jacobsen GK, McGowan SJ, Pfeifer SP, et al: Activating mutations in FGFR3 and HRAS revealed a shared genetic origin for congenital disorders and testicular tumors. Nat Genet 2009;41:1247-1252. 